\title{
FLUXOS MIGRATÓRIOS CONTEMPORÂNEOS: DESDOBRAMENTOS NO BRASIL
}

\author{
Joseane Mariéle Schuck Pinto ${ }^{1}$
}

Resumo: O Brasil vem se mostrando um país de intensa procura por parte dos migrantes, principalmente no que se refere às solicitações de refúgio e as adesões ao Programa de Reassentamento Regional. Desta forma nota-se relevante analisar os desdobramentos deste contexto no país e a atuação do Programa de Reassentamento no Estado do Rio Grande do Sul, que conta com a participação de órgãos estatais e de organizações não governamentais. O presente terá ainda por finalidade averiguar a atuação da Associação Antônio Vieira e seus parceiros no que tange a prática do referido Programa. Para tanto, se utilizou de métodos como observação participativa e de entrevistas semi-estruturadas junto a ASAV, Comirat, e demais parceiros, além de pesquisas documentais. Por fim, depreende-se deste estudo que o Programa além de ser uma solução duradoura para os refugiados, possui um viés humanitário e mostra-se fundamental na luta pela proteção, assistência e acolhimento aos refugiados.

Palavras-chave: Programa de Reassentamento Regional. Refugiados.

Abstract: Brazil has been a popular country with intense demand from migrants,
particularly with regard to asylum applications and acceptances to the Regional
Resettlement Program. Thus, the analysis of the outcomes of this scenario in the
country and the work of the Resettlement Program in the State of Rio Grande do

1 Advogada. Especialista em Relações Internacionais e Diplomacia pela Universidade do Vale do Rio dos Sinos/RS. Mestranda pelo Programa de Pós Graduação em Ciências Sociais pela mesma Universidade. Membro do grupo Núcleo de Direitos Humanos (NDH), na mesma instituição. Bolsista Fundo de Apoio Padre Milton Valente Unisinos e pesquisadora sobre fluxos migratórios e refugiados. E-mail: joseane.ms@terra.com. br. Currículo Lattes: http://lattes.cnpq.br/1297579135532782. 


\begin{abstract}
Sul with the participation of state agencies and non-governmental organizations is relevant. This paper also aims to establish the performance of the Antônio Vieira Association and its partners regarding the implementation of the such program. To do so, some methods were used; such as: participant observation and semi-structured interviews with ASAV, Comirat and other partners, and also documentary research. Finally, this study shows that the Program is not only a durable solution for refugees, but it also has a humanitarian bias and proves to be crucial in the fight for protection, support and care of refugees.
\end{abstract}

Keywords: Regional Resettlement Program. Refugees.

\section{CONSIDERAÇÕES INICIAIS}

Verifica-se que os movimentos migratórios tem sido característica marcante das últimas décadas no cenário internacional globalizado, acarretando em um fluxo de refugiados que passam a necessitar de ajuda humanitária internacional. Estes grupos forçadamente abandonam seus lares na busca de um novo lugar, a fim de que possam reconstruir suas vidas e readquirir sua dignidade. $\mathrm{O}$ presente ensaio tem por finalidade trazer à tona, dentro do contexto de mobilidade humana, a temática dos refugiados e seus desdobramentos no Brasil, uma vez que estes fluxos migratórios crescentes acabam possibilitando o desrespeito aos Direitos Humanos e a perda da dignidade humana dos refugiados.

O Brasil, por sua vez vem se mostrando um país de intensa procura por parte dos migrantes, principalmente no que se refere às solicitações de refúgio, eis que é signatário dos principais tratados internacionais de Direitos Huma- nos, assim como é parte na Convenção das Nações Unidas de 1951 sobre o Estatuto dos Refugiados, do Protocolo de 1967, da Convenção das Nações Unidas de 1954 sobre o Estatuto dos Apátridas e, posteriormente, em outubro de 2007, ratificou a Convenção da ONU de 1961 para Redução dos Casos de Apatridia, mas também tem recebido forte demanda no que diz respeito às solicitações de adesão ao Programa de Reassentamento Regional Solidário, haja vista caracterizar-se por ser uma das soluções duradouras para aqueles refugiados que por questões de segurança ou integração não podem permanecer no primeiro país de acolhida nem retornar ao de origem.

Cumpre destacar que o Programa de Reassentamento tem sua forte atuação no Estado do Rio Grande do Sul, que através da Associação Antônio Vieira, principal articuladora responsável pela infraestrutura e acolhimento dos refugiados, em atuação conjunta com Alto Comissariado das Nações Unidas para Refugiados e com o Comitê Nacional 
para Refugiados e demais parceiros, tem reassentado famílias de refugiados oriundos dos deslocamentos forçados.

\section{A QUESTÃO DO REFÚGIO NO BRASIL NAS ÚLTIMAS DÉCADAS E A HOSPITALIDADE}

Primeiramente, importante referir que a Segunda Guerra Mundial foi o referencial histórico na demarcação do tema envolvendo os refugiados, sendo que mais de 40 milhões de pessoas provenientes da Europa deslocaramse por ocasião da guerra, muito embora a Primeira Guerra Mundial tenha sido a responsável pelo aparecimento de um elevado número de refugiados e apátridas (HOBSBAWM, 1995, p. 58). Já, na década de 1960, a descolonização afro-asiática gerou novos fluxos de refugiados e nas décadas de 1970 e 1980 surgiram mais de 02 milhões de deslocados na América Latina, em razão dos regimes ditatoriais responsáveis por conflitos armados (ANDRADE, 1998, p. 400).

O fenômeno da globalização fomentou para novos deslocamentos e deslocados, em um contexto internacional marcado por conflitos, guerras civis, perseguições por racismo, ideologias políticas que acarretam em violações aos Direitos Humanos e o aumento diário de grupos de vulneráveis que passa a necessitar de ajuda humanitária internacional. Sem contar nas dificuldades que estas pessoas encontram pelo caminho, podendo ser vítimas de violência, de ameaças, de exploração sexual, neste caso principalmente as crianças e mulheres, além do tráfico de pessoas.

A temática envolvendo os refugiados obteve maior relevância no cenário nacional a partir do retorno da democracia, juntamente com o advento da Constituição Federal de 1988, eis que o artigo $4^{\circ}$ dispõe sobre a prevalência dos Direitos Humanos como o princípio norteador das relações internacionais do Brasil. Desta forma a tarefa do país neste momento histórico ${ }^{2}$ foi a de construir a imagem de uma nação que prima pela ajuda huma-

2 “A partir de março de 1989, com a transferência do escritório do Acnur para Brasília, finalmente estreita-se a relação entre este órgão subsidiário da ONU e as autoridades brasileiras. Após a mudança para a capital, o governo declara, com a promulgação do Decreto $n^{0}$ 98.602, de 19 de dezembro de 1989, sua opção pela alternativa (b) da Convenção de 1951, Artigo 1o, B (1), removendo desta forma a limitação geográfica e abrindo a possibilidade para que refugiados de qualquer lugar do mundo pudessem ser reconhecidos como tais no território brasileiro. O escritório do Acnur em Brasília continuou a avançar de forma significativa: em 3 de dezembro de 1990, o Brasil retirou suas reservas aos artigos 15 e 17 da Convenção de 1951, medida que permitiu aos refugiados 
nitária e pela globalização dos Direitos Humanos, passando então a ser vista pela comunidade internacional com outros olhos (PIOVESAN, 1998, p. 33-34).

Na década de 1990, durante o governo de Fernando Henrique Cardoso - FHC, o tema dos Direitos Humanos teve destaque tanto na política externa quanto na política interna do país, e em 1996 houve o lançamento do Primeiro Programa Nacional dos Direitos Humanos, sendo que o governo solicitou ao ACNUR uma pauta para servir de incentivo, a fim da elaboração de uma legislação específica que trate da questão dos refugiados e solicitantes de refúgio. Finalizado o projeto de lei sobre refugiados, encaminhou-se o mesmo ao Congresso Nacional, que por sua vez o aprovou, tanto na Câmara dos Deputados quanto no Senado Federal, inclusive contou com apoio da Comissão de Direitos Humanos da Câmara dos Deputados, da Igreja católica e da Vice-Presidência da República. Há de se referir que o projeto de lei encaminhado para aprovação no Congresso
Nacional não incluía a definição ampla de refugiado, a qual só foi inserida, posteriormente pelo seu relator na Comissão de Constituição, Justiça e Redação da Câmara dos Deputados, o então deputado Aloysio Nunes Ferreira Filho (ANDRADE,1996, p. 7-12).

Desta forma, surge a Lei 9.474, de 22 de julho de 1997, que define os mecanismos para a implementação do Estatuto dos Refugiados de 1951, e determina outras providências, sendo a primeira legislação preocupada em abordar a temática na América Latina, além de contar com uma parceria tripartite (governo, sociedade civil e ACNUR). Assim como foi instituído o CONARE, órgão formado por sete membros, que representam, respectivamente, os Ministérios da Justiça, Relações Exteriores, Trabalho, Saúde, Educação e Esporte, o Departamento de Polícia Federal. As Cáritas Arquidiocesana, organização não governamental da Igreja Católica parceira do ACNUR no Brasil, oferecem assistência e programas de integração aos refugiados.

gozarem do direito de associação e de exercerem trabalho remunerado. Daí em diante, tentou-se estabelecer um procedimento e uma divisão de responsabilidades relativos ao processo de solicitação de refúgio. É interessante observar que o governo brasileiro promoveu essas medidas estimulado apenas por considerações humanitárias, visto que o número de refugiados residentes no território nacional não era nada expressivo - apenas 200 - e não constituía um problema à sociedade.” ANDRADE, José H. Fischel de e MARCOLINI, Adriana. A política brasileira de proteção e de reassentamento de refugiados - breves comentários sobre suas principais características. Rev. bras. polit. int., Brasília, v. 45, n. 1, p. 160-70, jan./jun. 2002. Disponível em: <http://dx.doi.org/10.1590/ S0034-73292002000100008>. Acesso em: 10 maio 2014. 
O solicitante de refúgio ao pleitear auxílio humanitário recebe inicialmente a proteção expressa de maneira formal em um documento. É o reinício ou início de sua cidadania, pois não raro, tratar-se do primeiro documento que recebe conferindo-lhe a condição de cidadão. Ainda, terá direito à documentação provisória, incluindo carteira de trabalho. Todas as solicitações de refúgio são analisadas pelo CONARE, e em caso de indeferimento, é possível apresentar recurso junto ao Ministro da Justiça. Importante destacar que o refugiado no Brasil tem os mesmos direitos e deveres que qualquer estrangeiro em situação regular no país. Ainda, a Constituição Federal de 1988, ao conceder tratamento igualitário aos brasileiros e estrangeiros residentes no país, consoante assevera o artigo $5^{\circ}$, assegura a estes a possibilidade de acesso às políticas públicas existentes, assim como a Lei 9.474/97, que por sua vez expressa o compromisso do Brasil com a causa humanitária do refúgio, chamando o país à efetivação destes direitos quando sinalizou para a implementação de políticas públicas para a integração dos refugiados. Em relação ao Programa de Reassentamento Regional Solidário, o seu início ocorreu em 10 de agosto de 1999, mediante a assinatura de um acordo pactuado entre o governo brasileiro e o ACNUR, incluindo este a legislação pertinente aos refugiados, qual seja, a Lei 9.474/97, em seu artigo 46, senão vejamos:

"[...] o reassentamento de refugiados no Brasil se efetuará de forma planificada e com participação coordenada dos órgãos estatais e, quando possível, de organizações não governamentais, identificando áreas de cooperação e de determinação de responsabilidades".

Tal programa visa ser utilizado como uma solução duradoura para àqueles refugiados que por questões de segurança ou integração não podem permanecer no primeiro país de acolhida nem retornar ao de origem. ${ }^{3}$ Nesse sentido cabe

3 "Em março de 2001, uma missão do Acnur visitou quatro cidades brasileiras, escolhidas pelo Ministério da Justiça para sediar os projetos-piloto de reassentamento a serem coordenados pelo Conare. A decisão de se fazer uma visita prévia às cidades derivou da preocupação das autoridades brasileiras em assegurar que os refugiados reassentados sejam bem recebidos e tenham uma boa integração nas comunidades locais. Nos contatos com representantes da sociedade civil, como as Câmaras de Comércio e Indústria, explicou-se a iniciativa de reassentamento e se solicitou o apoio local - sempre com uma boa receptividade. Em agosto de 2001 realizou-se, no Rio de Janeiro, um seminário, com a participação do Acnur, de ONGs e de autoridades do Governo federal, oportunidade na qual concluiu-se o planejamento do programa de reassentamento. Com base em critérios como tamanho, atividade econômica e origem étnica da população, o Ministério da Justiça escolheu as seguintes cidades para a fase inicial do programa de 
destacar o disposto no artigo $2^{\circ}$ da Resolução do CONARE n. 14, vejamos: "O Programa de Reassentamento Brasileiro está estruturado de forma tripartite, com a participação do Governo do Brasil, do Alto Comissariado das Nações Unidas para Refugiados e as organizações da sociedade civil implementadoras do programa." 4

O Brasil, assim recebe refugiados espontâneos e outros que são reassentados, vindos de outros países, no mesmo sentido Martin nos explica que:

"Regional protection is hardly a new concept. The vast majority of refugees have always found asylum within their regions of origin, generally in neighbouring countries. What is new is the interest of European and North American States in redirecting movements toward regional canters" (MARTIN, 2002, p. 34).

Com o advento do governo Luiz Inácio Lula da Silva, em 2003, a polí- tica sobre os refugiados manteve-se em destaque na agenda da política interna e externa do país, tratando a temática dentro do seguimento dos Direitos Humanos, bem como o governo preocupou-se em ampliar tal política com a criação do Programa Nacional de Direitos Humanos II. A expansão da política sobre refugiados teve suporte na legislação nacional promulgada pelo FHC, além das resoluções do CONARE, assim como se baseou no Programa de Reassentamento Regional Solidário, contido na Declaração e Plano de Ação do México ${ }^{5}$ sendo este programa considerado como uma solução durável para a questão dos refugiados. A partir deste desenvolvimento a respeito da política dos refugiados, o país passou a ser reconhecido pelo ACNUR como líder na América Latina. Ainda no decorrer deste governo houve a criação da Secretaria Especial de Direitos Humanos, passando a ser vinculada à Presi-

reassentamento: Porto Alegre (RS), Mogi das Cruzes (SP), Santa Maria Madalena (RJ) e Natal (RN). Autoridades locais e organizações não-governamentais, selecionadas pelo Ministério da Justiça, comprometeram-se em apoiar a iniciativa." FISCHEL, José H. de Andrade; MAROLINI, Adriana. A política brasileira de proteção e de reassentamento de refugiados - breves comentários sobre suas principais características. Rev. bras. polit. int., Brasília, v. 45, n. 1, p. 173, jan./jun. 2002. Disponível em: <http://dx.doi.org/10.1590/ S0034-73292002000100008>. Acesso em: 10 maio 2014.

4 Disponível em: <http://portal.mj.gov.br/>. Acesso em: 14 abr. 2014.

5 "Em março de 2001, uma missão do Acnur visitou quatro cidades brasileiras, escolhidas pelo Ministério da Justiça para sediar os projetos-piloto de reassentamento a serem coordenados pelo Conare. A decisão de se fazer uma visita prévia às cidades derivou da preocupação das autoridades brasileiras em assegurar que os refugiados reassentados sejam bem recebidos e tenham uma boa integração nas comunidades locais. 
dência da República, além da elaboração em 2010, no final do segundo mandato de Lula, do Programa Nacional de Direitos Humanos III. E, em 29 de dezembro de 2011 é publicada a Resolução Normativa do CONARE n. 14, que versa sobre o Programa de Reassentamento brasileiro (CORREA, 2007, p. 739-61).

Importante referir que na América Latina há uma preocupação no sentido de compartilhar as responsabilidades de proteção e integração aos refugiados entre as nações, razão pela qual se percebe o crescimento do número de refugiados reassentados no Brasil por meio do Programa de Reassentamento Regional Solidário, bem como o aperfeiçoamento dos Programas de proteção e assistência a grupos de refugiados viabiliza a reconstrução das vidas destas pessoas e permite que alcancem a autossuficiência e à cidadania perdida. O refugiado ao aderir ao Programa passa a receber, caso seja necessário, uma atenção médica e psicológica especial, uma vez que os reassentados são refugiados que não conseguiram integrar-se no país que solicitaram refúgio, pelos mais diversos motivos, seja cultural, religioso, social, entre outros. Ou até mesmo foram vítimas de violência ou sofreram tortura. Sem contar na situação das mulheres, sendo que muitas delas são as solicitantes de reassentamento, uma vez que foram vítimas de exploração, assédio sexual e violência das mais variadas.

O primeiro reassentamento de refugiados no Brasil ocorreu em 2002, com a chegada de 23 afegãos ao Estado do Rio Grande do Sul. Até o final de 2013, conforme dados do CONARE, contabiliza-se que cerca de 470 refugiados estão reassentados em território brasileiro, dentre eles: 324 colombianos, 96 palestinos, 27 equatorianos, 09 afegãos, 03 venezuelanas, 03 apátridas, 01 congolês, 01 costarriquenha, 01 iraquiana, 01 jordaniana, 01 libanesa ${ }^{6}$ O Brasil vem demonstrando preocupação com o aumento significativo de refugiados Colombianos, em razão dos problemas advindos da guerra civil no país, sem contar na dificuldade dos Colombianos em integrarem-se na Costa Rica e no Equador, países em que solicitaram o status de refugiado.

Em julho de 2013, o CONARE aprovou o pedido de reassentamento de 58 Colombianos que residiam no Equador e que tiveram dificuldades de adaptação neste país, local onde solicitaram o status de refúgio. Razão pela qual vieram a requerer junto as Nações Unidas a adesão ao Programa de Reassentamento solidário e a vinda ao Brasil, que por sua vez encaminhou estes refugiados aos Programas de reassentamento, dentre

6 Disponível em: <http://portal.mj.gov.br/data/Pages/MJ7CBDB5BEITEMID2148C6C8145E4B0F841F7CC33DF09DD6PTBRIE.htm>. Acesso em: 12 abr. 2014. 
eles 33 foram encaminhados para o Rio Grande do Sul, por meio da ASAV, e 25 foram recebidos pelo Centro de Defesa dos Direitos Humanos de Garulhos CDDH, no Estado de São Paulo. ${ }^{7}$

Não obstante o Brasil ser um país pioneiro no que diz respeito à liderança na proteção internacional dos refugiados, sendo o primeiro país do CONESUL a ratificar a Convenção relativa ao Estatuto dos Refugiados de 1951, no ano de 1960, bem como atuar conjuntamente com o ACNUR na defesa dos Direitos Humanos e da cidadania dos deslocados forçados, seja por meio do reassentamento solidário, seja pelo acolhimento e pela proteção internacional a estas pessoas, nota-se que ainda há um longo caminho a percorrer no que diz respeito ao enfrentamento da questão migratória no país que merece ser ampliada, pois diante do cenário que se desenha com as guerras civis, com violência, com desastres ambientais que assolam a humanidade, restam ainda outros problemas a serem superados, como por exemplo, a adoção de políticas em prol do fechamento de fronteiras por parte de países da Europa e dos EUA. Desta forma, só será possível protegê-los das mais variadas violações aos seus direitos como seres humanos se houverem instrumentos que propiciem o acolhimento e a integração destes refugiados à sociedade brasileira, obtendo, o mais rapidamente possível, a autossuficiência e a cidadania.

Além disso, há o grave problema da integração dos refugiados ao inseriremse na sociedade brasileira, enfrentando obstáculos como a língua, a cultura, a efetivação de direitos fundamentais, ou seja, direito ao emprego, à saúde, à moradia, à educação, entre outros. Nesse sentido, para que se concretize a ajuda humanitária e a integração dos refugiados no cenário nacional, a ACNUR, através de convênios conta com o apoio de atores não-estatais, isto é, organizações não-governamentais, como é o caso do Rio Grande do Sul da ASAV, e em São Paulo e no Rio de Janeiro estão presentes as Cáritas Arquidiocesana, ambas vinculadas a Igreja Católica. Em relação ao acolhimento, o Brasil ao expressar o compromisso com a causa humanitária do refúgio, se comprometeu a acolher os migrantes, apresentando-se na comunidade internacional como um país hospitaleiro. ${ }^{8}$

O conceito de hospitalidade, desenvolvido por Derrida, via Levinas, nos revela a possibilidade, por vezes negada, e por isso mesmo questiona-

7 Disponível em: <http://portal.mj.gov.br/>. Acesso em: 12 abr. 2014.

$8 \mathrm{O}$ termo Hospitalidade, segundo as definições do dicionário, refere ao ato de acolher, de receber um hóspede em casa. Ser hospitaleiro significa hospedar bem àquele que não é da nossa família. Uma lógica da amabilidade parece permear no sentido do termo, 
da, de uma acolhida incondicional do outro enquanto outro. De acordo com Derrida, a lei da hospitalidade aparece como uma lei paradoxal, uma vez que a regra que determina a submissão do estrangeiro às leis do país anfitrião deveria também resguardar o respeito e a aceitação de sua diferença por meio de uma "ética da hospitalidade" (DERRIDA, 2003, p. 15). Desta forma, verifica-se que o papel desempenhado pelas organizações não governamentais diante da acolhida e da integração dos refugiados está galgado na ética da hospitalidade, da tolerância, do respeito ao outro. Tanto o acolhimento quanto à hospitalidade permitirão que se devolva à cidadania perdida e que seja proporcionado o acesso igualitário aos direitos fundamentais assegurados pela Constituição Federal, sem privilegiá-los, ou seja, os refugiados e os reassentados devem receber o mesmo tratamento despendido aos cidadãos brasileiros.

Derrida (2004, p. 66) traz à tona a existência da hospitalidade denominada de condicionada, seja por direitos, seja por deveres que devem ser seguidos pelo que chega e pelo que acolhe, e este tipo de hospitalidade se encaixa no contexto da concessão de refúgio no Brasil, assim como acerca do programa de reassentamento que prima pelo acolhimento e pela integração dos reassentados. A hospitalidade deve ser vista como uma das virtudes necessárias para o mundo atual de deslocamentos e de deslocados, face à ocorrência de conflitos, guerras civis, perseguições por racismo, ideologias políticas, acarretando em violações aos Direitos Humanos, sendo que esses grupos de vulneráveis passam a necessitar de ajuda humanitária internacional. Nota-se que diante deste contexto mundial é imperioso que prevaleça a mútua acolhida pelos países hospitaleiros, no sentido de prevalecer à abertura generosa de fronteiras, aderindo à hospitalidade condicional, vislumbrando as diferenças como diferenças e não como desigualdade e inferioridade. Em tempos em que o acolhimento do outro se dá de forma cada vez mais restrita, em que a hospitalidade se torna cada vez mais condicionada às suas leis, a questão das cidades-refúgio ganham maior

O homem gentil, hospitaleiro, prepara a chegada do outro e o recebe. Se pensarmos a questão dos estrangeiros e do Estado de Direito pareceria que uma atitude gentil predispõe ou deveria predispor aos Estados republicanos, às democracias, a acolher o estrangeiro, o outro. Por pura gentileza dar-se-ia o lugar a quem solicita, o outro. PEREZ, Daniel Ornar. Os significados dos conceitos de hospitalidade em kant e a problemática do estrangeiro. konvergencias Filosofia y Culturas in Diálogo. ISSN 1669-9092. Afio IV N ${ }^{\circ} 15$ Segundo Cuatrimestre 2007. Disponível em: <http://www.konvergencias.net/ danieloperez132.pdf>. Acesso em: 03 maio 2014. 
importância no cenário ético-político internacional.

Nesta esteira, vale referir Ponte Neto:

O Governo do Brasil será responsável pela recepção e facilitará a integração dos refugiados reassentados, contando com o apoio do ACNUR e de organizações governamentais ou não governamentais. O ACNUR contribuirá financeiramente com a integração dos refugiados por meio de um projeto no qual se designará a entidade executora. Tal projeto será executado por tal entidade, em coordenação com o ACNUR (PONTE NETO, 2003, p. 163).

Ainda sobre o tema, Araújo menciona que:

O desafio de ser refugiado é o desafio que governos e sociedades de boa vontade têm que enfrentar: como criar e fazer valer políticas humanitárias de inclusão social? A triste realidade do fluxo de refugiados no mundo representa uma das maiores tragédias dos nossos dias e o seu destino se relaciona diretamente com questões políticas e afeitas aos direitos humanos que, longe de representar uma preocupação apenas dos governos, deveria ser, em larga medida, urna preocupação atinente a cada um de nós. Forçado a deixar seu país, perambula pelo mundo a esmolar cidadania, a implorar por itens essenciais ao projeto de felicidade humana: liberdade, apreço, emprego, educação, saúde. O descaso dos países ricos para com este problema é um poderoso agravante em uma há muito tem mostrado ser insustentável (ARAÚJO, 2003, p. 35).

Por fim, o Brasil diante da comunidade internacional é reconhecido por sua postura humanitária em relação ao atendimento aos refugiados, não obstante a problemas internos relacionados ao âmbito social, econômico e político, sendo que a busca da integração é a forma de refúgio mais plena e, contudo mais complexa, uma vez que ultrapassa as expressões iniciais de acolhida, da documentação, do atendimento a necessidades básicas e imediatas. Resta comprovada que é considerada mais profunda e abrangente.

\section{O PROGRAMA REGIONAL DE REASSENTAMENTO AOS REFUGIADOS NO ESTADO DO RIO GRANDE DO SUL: PERSPECTIVAS E ATUAÇÕES}

No que concerne à solução duradoura para os refugiados, esta ocorre por meio do Programa Regional de Reassentamento Solidário, no Estado do Rio Grande do Sul, que conta com a forte atuação da ASAV - mantenedora da Rede Jesuíta de Educação, vinculada ao ACNUR e ao CONARE, e desempenha há 10 anos o trabalho de reassentar refugiados, encaminhando-os aos Municípios parceiros, sendo, portanto a 
implementadora deste programa. Assim como possibilita a infraestrutura e as condições necessárias para acolhimento e a inclusão dessa população nas diversas comunidades já pré-definidas para o reassentamento. ${ }^{9}$

De acordo com a coordenadora do Projeto de Reassentamento Solidário da ASAV, Karin Wapechowski, até julho de 2013 foram acolhidos 262 refugiados, os quais aderiram ao programa de reassentamento refugiados oriundos do Afeganistão, Colômbia e Paquistão, residindo em 15 Municípios parceiros, quais sejam: Sapucaia do Sul, São Leopoldo, Sapiranga, Santa Maria, Passo Fundo, Guaporé, Bento Gonçalves, Caxias do Sul, Serafina Corrêa, Rio Grande, Pelotas, Venâncio Aires, etc. Em junho de 2013 a coordenadora do programa fora convidada pelo CONARE e ACNUR, a participar da missão de entrevistas de casos de candidatos Colombianos, que já possuem o status de refugiado e passam a solicitar adesão ao programa brasileiro de reassentamento solidário, ocorrido em Quito, no Equador. Tal missão resultou na aprovação de 29 famílias de refugiados, totalizando um número de 106 refugiados Colombianos aptos a inte- grarem o programa no Brasil, dos quais fizeram adesão ao programa no Estado do RS nove famílias, resultando em 34 refugiados Colombianos. ${ }^{10}$

O Programa de Reassentamento apresenta-se como uma solução duradoura ao enfrentamento da problemática dos refugiados, vindo ao encontro o papel desempenhado pela ASAV que atua no sentido de prestar o acolhimento por meio da inclusão social, permitindo a ressocialização e as garantias dos direitos fundamentais. O Estado do RS tem reassentado os grupos de vulneráveis oriundos dos deslocamentos forçados em razão da guerra civil na Colômbia. Além disso, muitos foram ameaçados de morte pelas Forças Armadas Revolucionárias - FARC, vendo-se obrigados a abandonarem seu país de origem em busca de refúgio no Equador, passando inclusive a viver em campos de refugiados, cujas condições de vida são sub-humanas, sem infraestrutura de serviços básicos de saúde, de educação, de dignidade e cidadania, sofrendo as mais variadas formas de violência física, abalo emocional e psicológico. As mulheres e crianças oriundas do refúgio acabam sendo as mais atingidas, uma vez que suportam a violência e exploração se-

9 Dados obtidos em entrevista semi-estruturada, concedida em 15 de agosto de 2013, na sede da ASAV em Porto Alegre, pela coordenadora do Projeto de Reassentamento Regional Solidário no RS, Karin Wapechowski.

10 Dados obtidos em entrevista semi-estruturada, concedida em 15 de agosto de 2013, na sede da ASAV em Porto Alegre, pela coordenadora do Projeto de Reassentamento Regional Solidário no RS, Karin Wapechowski. 
xual. E, é nesse contexto que a ASAV vem ao encontro da prestação de auxílio humanitário, solicitando aos Agentes de Saúde Pública dos Municípios, que prestem a essas pessoas vítimas deste longo processo de refúgio, o auxílio e o acompanhamento especial, tanto médico quanto psicológico, por um período de 03 a 04 meses. ${ }^{11}$

Ademais, a ASAV no ano de 2004 alterou o seu Estatuto, no sentido de possibilitar locações de imóveis junto aos Municípios parceiros, em nome da Associação, com intuito de serem utilizados como moradia aos refugiados reassentados. Esta locação perdura aproximadamente pelo período de 01 ano, e os valores dos aluguéis são custeados pelo ACNUR. Outro fator a ser destacado está na preocupação da ASAV em não concentrar mais de 02 famílias por cidade, havendo, portanto uma dispersão territorial no que tange aos reassentamentos visando à segurança e oportunidades de integração local destas pessoas à sociedade na qual estão sendo inseridas. Ainda, ocorre com cada família reassentada uma análise conjunta, a fim de elaborar o plano de integração social mais adequado a realidade daqueles membros, levando em conta as questões que envolvem o âmbito profissional, educacional e cultural de cada refugiado. ${ }^{12}$

O governo do Estado tem se mostrado um parceiro da ASAV na implementação do programa de reassentamento, sendo que em 22 de outubro de 2012, o governador do Estado, Tarso Genro, por meio de Decreto N. 49.729, instituiu o Comitê de atenção a migrantes, refugiados, apátridas e vítimas de tráfico de pessoas no Estado do RS - Comirat, ${ }^{13}$ visando à promoção de ações voltadas à integração dessas categorias no Estado, bem como outras ações constantes no decreto. Consoante assevera a Coordenadora do Comirat e diretora da Secretaria de Justiça e Direitos Humanos do Estado, Tâmara Biolo Soares, o trabalho do Comitê é produzir diagnóstico e conhecimento acerca dos processos migratórios e deslocamentos forçados no RS, dialogando com política do Estado, inclusive salienta que o Estado pretende estender os programas "Mais Igual e o RS Mais Renda" a refugiados que ingressam no Estado. O Comirat

11 Dados obtidos em entrevista semi-estruturada, concedida em 15 de agosto de 2013, na sede da ASAV em Porto Alegre, pela coordenadora do Projeto de Reassentamento Regional Solidário no RS, Karin Wapechowski.

12 Dados obtidos em entrevista semi-estruturada, concedida em 15 de agosto de 2013, na sede da ASAV em Porto Alegre, pela coordenadora do Projeto de Reassentamento Regional Solidário no RS, Karin Wapechowski.

13 Disponível em: <http://www.sjdh.rs.gov.br/?model=conteudo\&menu=1\&i$\mathrm{d}=1612 \&$ pg $=>$. Acesso em: 30 jul. 2013. 
deve oferecer assistência para que os migrantes obtenham a documentação exigida e alcancem inserção social. Desta forma o Comitê, que se encontra em fase de discussão e elaboração de seu Regimento Interno, visa à elaboração de políticas públicas que enfrentem a problemática envolvendo os migrantes, refugiados, apátridas, vítimas de tráfico de pessoas no RS, sendo que sua implementação caberá ao governo do Estado, assim como aos Municípios.

Nesse sentido, vem ao encontro o que traz à tona Pinto, vejamos:

Contudo, para que a integração local e o reassentamento possam oferecer condições de vida digna aos refugiados, um envolvimento de todos os entes da Federação brasileira é necessário, juntamente com o ACNUR e entidades organizadas da sociedade civil. Na República Federativa Brasileira, a determinação do status de refugiado é de competência da União, mais precisamente de uma entidade despersonalizada vinculada ao Ministério da Justiça, o Comitê Nacional de Refugiados, CONARE. Cabe também a este órgão "orientar e coordenar as ações necessárias à eficácia da proteção, assistência e apoio jurídico aos refugiados" (art. 12, IV, Lei 9.474). Destaque-se que esta última competência diz respeito a missões de orientação e coordenação de ações, o que indica que este órgão não atua sozinho no que tange as medidas necessárias à eficácia da proteção, da assistência e do apoio jurídico aos refugiados. Assim, Estados e Municípios também podem implementar ações nesse sentido, ao lado de ONGs e do próprio ACNUR. O envolvimento de tais entes federados não somente coaduna-se com os mandamentos constitucionais da Federação brasileira (cf. infra), como se torna essencial, num país de dimensões continentais, para que a integração local e o reassentamento de refugiados prosperem, trazendo benefícios tanto para os refugiados, quanto para o Estado e a sociedade brasileira (PINTO, 2011, p. 181-182).

Percebe-se que o Estado do RS ao promulgar o Decreto 49.729 de 2012, está voltado a enfrentar questões envolvendo migrações forçadas, reafirmando, por sua vez os fundamentos da República Federativa do Brasil, conforme o disposto no artigo $1^{\circ}$, e os princípios que regem as Relações Internacionais contidos no artigo $4^{\circ}$, ambos da Constituição Federal de 1988 que objetivam segundo versa o decreto

"a necessidade de adequar instrumentos legislativos e fortalecer instâncias de elaboração de ações da política que garantam e assegurem o acesso aos migrantes e aos refugiados e propiciem atualização do debate sobre ações dirigidas à mobilidade humana conforme os princípios constitucionais que garantem a dignidade humana." 14

14 Decreto $\mathrm{n}^{\circ}$ 49.729, de 22 de outubro de 2012. Disponível em: <http://www.al.rs.gov. br/legis/M010/M0100099.ASP?Hid_Tipo=TEXTO\&Hid_TodasNormas=58497\&hTexto=\&Hid_IDNorma=58497>. Acesso em: 29 ago. 2013. 
Nesta esteira o artigo $1^{\circ}$ do presente Decreto objetiva através do Comitê a implementação de políticas públicas que assegurem a promoção dos direitos humanos dos vulneráveis, vejamos:

"Fica instituído o Comitê de Atenção a Migrantes, Refugiados, Apátridas e Vítimas de Tráfico de Pessoas no Estado do Rio Grande do Sul-Comirat/RS, no âmbito da Secretaria da Justiça e dos Direitos Humanos, com o objetivo de promover e garantir o respeito aos direitos humanos das pessoas vulneráveis que se encontram em mobilidade no Estado do Rio Grande do Sul." 15

\section{A competência do Comirat encon-} tra-se disposta no artigo $3^{\circ}$ do Decreto que vem:

I - elaborar, implementar e monitorar o Plano Estadual de Políticas de Atenção a Migrantes, Refugiados, Apátridas e Vítimas de Tráfico de Pessoas no Estado do Rio Grande do Sul, com o objetivo de facilitar o acesso das categorias previstas no art. $1^{\circ}, \S 1^{\circ}$ deste Decreto às políticas públicas; II - monitorar as ações institucionais que dizem respeito à mobilidade humana e que interpelam as categorias deste Decreto; III - propor ações para solucionar as questões relativas aos migrantes indocumentados; IV - propor a constituição de serviços específicos para o atendimento dos migrantes, assegurando o seu acesso a bens e serviços públicos, por inter- médio de atendimento humanizado e adequado a sua situação; $\mathrm{V}$ - promover ações e coordenar iniciativas de atenção, promoção e defesa das categorias de que trata este Decreto no Estado do Rio Grande do Sul, garantindo um atendimento livre de preconceito e discriminação por motivos de origem, raça, sexo, cor, idade, crença ou pertença a grupo social; VI - apoiar a promoção de ações voltadas à integração dessas categorias no Estado do Rio Grande do Sul; VII - orientar e formar agentes públicos, privados e membros da sociedade civil sobre a realidade da mobilidade humana, com foco na garantia dos direitos e deveres dessas categorias em condições de respeito à dignidade de cada pessoa, independentemente de sua origem; VIII - orientar as ações de prevenção a violações de direitos humanos das pessoas em mobilidade, visando coibir a sua ocorrência; IX - informar às instâncias competentes sobre denúncias de violação de direitos dos migrantes, para apuração e responsabilização; X reunir, atualizar e estimular estudos, pesquisas e relatórios sobre o fenômeno da mobilidade humana; XI - apoiar ações e fóruns de debates sobre a revisão da legislação nacional, especificamente a Lei Federal $n^{\circ}$. 6.815, de 19 de agosto de 1980, Estatuto do Estrangeiro; e XII - apoiar debates e ações com o objetivo de ratificar a Convenção Internacional sobre os Direitos dos Trabalhadores Migrantes e suas famílias, aprovada pela Assembleia Geral da ONU, por meio da Resolução $n^{\circ} 45 / 158$, em 18

15 Decreto $n^{\circ} 49.729$, de 22 de outubro de 2012. Disponível em: <http://www.al.rs.gov. br/legis/M010/M0100099.ASP?Hid_Tipo=TEXTO\&Hid_TodasNormas=58497\&hTexto $=\&$ Hid_IDNorma $=58497>$. Acesso em: 29 ago. 2013. 
de dezembro de 1990, que estabelece normas de tratamento igualitário entre trabalhadores nacionais e estrangeiros e atribui direitos humanos e fundamentais a todos os trabalhadores migrantes, legais ou irregulares. ${ }^{16}$

Verifica-se, portanto que a criação do Comirat/RS vem corroborar no fortalecimento do trabalho desempenhado no Estado pela ASAV, possibilitando por meio de ações e de políticas públicas eficazes a garantia e proteção aos Direitos Humanos e a promoção da cidadania, pois a partir do acolhimento será possível a efetiva integração local dos refugiados reassentados.

Neste prisma, verifica-se que a ASAV atua no sentido de assegurar as providências necessárias para o efetivo exercício dos direitos humanos destes refugiados, como à educação, à moradia, à saúde, o trabalho, etc, prestando o auxílio necessário às famílias. No entanto, insta destacar que o programa não visa beneficiar aos refugiados, pelo contrário, eles terão os mesmos direitos e deveres que os cidadãos brasileiros. Nota-se que o programa efetivado pela ASAV tem um viés humanitário, haja vista que atua em conjunto com o ACNUR, CONARE, Governo do Estado e com os Municípios, objetivando, por meio da acolhida, realizar a integração dos grupos de refugiados na comunidade local.
Este trabalho garante o respeito aos direitos humanos dessas pessoas, devolvendo-lhes o lar que lhes foi retirado, e por sua vez à sua dignidade, haja vista tratar-se de seres humanos, nesse sentido Souza (2005, p. 11) assevera que: "O ser humano é, ele mesmo, um mundo humano, e ferir a dignidade de alguém significa ferir o mundo inteiro". E, é desta forma que a ASAV vem atuando em prol do acolhimento que proporciona um novo recomeço aos grupos e famílias de refugiados que aderirem ao programa.

Neste contexto de refúgio, os grupos oriundos de outras nações enfrentam as mais diversas dificuldades de convivência, como por exemplo, uma nova língua, cultura, sendo imperioso vislumbrarem um ambiente propício de integração na localidade em que estão sendo inseridos, a fim de amenizar os obstáculos enfrentados. Se o ambiente estiver fortemente comprometido com a ideia de tolerância e de cidadania compartilhadas a inserção e a integração dos grupos de refugiados irá proporcionar um recomeço de vida com dignidade (MELO, 2001, p. 278-279).

Cumpre referir também o papel desempenhado pelas Cátedras Sérgio Vieira de Mello no Estado do Rio Grande do Sul, que se localizam na Universidade Federal do RS - UFRGS e na Universidade do Vale do Rio dos Sinos

16 Disponível em: <http://portal.mj.gov.br>. Acesso em: 26 abr. 2014. 
- UNISINOS, que a partir dos trabalhos realizados pela comunidade acadêmica conjuntamente com a sociedade civil, podem neutralizar os pré-conceitos e percepções negativas advindas da sociedade em relação à questão da acolhida aos refugiados, uma vez que o conhecimento qualificado e disponível à população poderá ser um facilitador da integração local dos reassentados, assim como dos solicitantes de refúgio. Nota-se, que a atuação conjunta da Cátedra Sérgio Vieira de Mello na Universidade e da ASAV é primordial no sentido de difundir informações, possibilitando a acolhida de refugiados e a valorização e difusão da cultura dessas pessoas junto à comunidade local (PINTO, 2013, p. 9-10).

No que diz respeito aos fatores culturais, verifica-se que no processo de integração local dos refugiados há uma abertura da cultura política tanto por parte dos governos, quanto em relação à sociedade, contudo ainda se percebe as dificuldades à adaptação do refugiado à nova sociedade na qual foi inserido, haja vista deparar-se com uma língua e cultura que diferem da sua, e claro algumas localidades podem mostrar-se não receptivas aos refugiados, sobretudo em virtude das diferenças culturais existentes entre eles. Esta integração tem como marco inicial a solicitação de refúgio, tendo em vista que o solicitante, enquanto aguarda a tramitação legal do procedimento de refúgio, já procura se inserir na sociedade da qual passa a fazer parte, seja através do estudo do novo idioma, seja por meio da inserção no mercado de trabalho. Nesse sentido o maior desafio a ser enfrentado em relação à integração local está nas diferenças culturais, tendo em vista que os refugiados passam a interagir num novo ambiente que pode apresentar traços culturais distintos de sua comunidade de origem.

Quanto maior a proximidade cultural, social, linguística e étnica entre o país de origem e o de destino, em tese, esse processo se revela mais fácil e os resultados, mais promissores, bem como as diferenças culturais não podem ser obstáculos à universalização dos direitos humanos, uma vez que necessitam ser respeitados e protegidos, a fim do reconhecimento desses direitos. Além disso, os refugiados podem representar uma ótima oportunidade para o desenvolvimento econômico do país que os recebe, mas para tanto é preciso que haja o reconhecimento de que a integração tem maior chance de obter sucesso em um ambiente em que os recém-chegados possam manter sua cultura, religião, integridade étnica e sua identidade cultural enquanto que ao mesmo tempo sejam encorajados a participar e tenham acesso à cultura da sociedade que os recebe.

\section{CONSIDERAÇÕES FINAIS}

Neste contexto de deslocamentos e deslocados os países em desenvol- 
vimento assumem relevante papel no que se refere à proteção aos refugiados, vindo ao encontro a atuação brasileira, sendo que o país se consolidou como o principal doador do ACNUR entre os países emergentes, com US\$ 3,5 milhões doados em 2010, US\$3,7 milhões em 2011 e US\$ 3,6 milhões em 2012. (ACNUR, 2013). Além de abraçar a causa ao elaborar uma legislação protetiva e de assistência, bem como a instituir um órgão específico que cuide dessa questão, assumindo com o auxílio humanitário a garantia dos Direitos Humanos, o acolhimento e a hospitalidade aos refugiados, vejamos:

Os preceitos desta Lei deverão ser interpretados em harmonia com a Declaração Universal dos Direitos do Homem de 1948, com a Convenção sobre o Estatuto dos Refugiados de 1951, com o Protocolo sobre o Estatuto dos Refugiados de 1967 e com todo dispositivo pertinente de instrumentos internacional de proteção aos direitos humanos com o qual o Governo brasileiro estiver comprometido. ${ }^{17}$

No mesmo sentido, a criação do CONARE foi fundamental vindo ao encontro das questões relativas ao refúgio no Brasil, sendo o órgão responsável por orientar e coordenar as ações necessárias à eficácia da proteção, assistência e apoio jurídico aos refugiados. Vindo corroborar o Programa de Reassenta- mento Regional Solidário, sendo um importante instrumento de solução duradoura para aqueles refugiados que por questões de segurança ou integração não podem permanecer no primeiro país de acolhida nem retornar ao de origem, contando com o apoio e a participação do governo brasileiro, do ACNUR e das organizações não governamentais. E, é nesse sentido que à atuação destas organizações conjuntamente com o CONARE e o ACNUR se mostram fundamentais na luta pela proteção, assistência e acolhimento aos refugiados.

Esta atuação conjunta entre ASAV, Governo do Estado, Municípios parceiros e as Cátedras Sérgio Vieira de Mello da UFRGS e da Unisinos, propiciam um novo recomeço para os refugiados, vindo colaborar e fortalecer este apoio a criação do Comirate/RS, cujo objetivo é implementar políticas públicas capazes de viabilizar o exercício dos direitos fundamentais, como o direito à educação, à moradia, à saúde, $o$ trabalho, entre outros. E no momento em que os refugiados realizam a adesão ao programa farão jus aos mesmos direitos concedidos aos cidadãos brasileiros. Assim, resta comprovado que o programa de reassentamento, além de ser uma solução duradora para a problemática do refúgio possui ainda um viés humanitário, no qual o acolhimento tem por finalidade a integração

17 Disponível em: <http://portal.mj.gov.br>. Acesso em: 26 abr. 2014. 
na comunidade local dos refugiados, e por conseqüência a possibilidade de alcançar a dignidade perdida, além da reconstrução de suas vidas.

O Brasil tem por característica a hospitalidade e diante da questão migratória prima pela abertura de fronteiras $\mathrm{e}$ pelo auxílio humanitário, nesta esteira importante destacar a posição do país em relação à crise que se desenha no cenário internacional, principalmente no que diz respeito à Síria, um país em guerra civil responsável por mais de dois milhões de sírios se tornando refugiados. De acordo com Paulo Abrão, que preside o CONARE “[...] o Brasil tem tradição de solidariedade e participará do esforço internacional para abrigar os cidadãos que fogem de uma possível guerra". Nesse sentido, recentemente o CONARE publicou a Resolução Normativa N. 17, que garante a concessão de visto humanitário especial a pessoas afetadas pelos conflitos armados na Síria e região que desejem chegar ao Brasil buscando refúgio. $\mathrm{O}$ visto especial será concedido pelo Ministério das Relações Exteriores e se estenderá também à família dessas pessoas deslocadas, assim como tal resolução normativa terá validade pelo prazo de 02 anos, podendo ser prorrogada. ${ }^{18}$
Apesar dos esforços do país no enfrentamento da questão do refúgio, ainda resta déficit democrático em relação aos estrangeiros, conforme assevera Paulo Abrão, tendo aumentado significativamente o fluxo migratório em direção ao Brasil. ${ }^{19}$ Diante deste contexto há uma preocupação do governo em repensar e reestruturar a questão migratória no país, a fim que se efetive os direitos humanos e por sua vez o auxílio humanitário. Ainda existem muitos obstáculos a serem superados, e um deles diz respeito à integração local, sendo que as diferenças culturais são na maioria das vezes significativas, tendo em vista que os refugiados passam a interagir em um novo ambiente que pode apresentar traços culturais distintos de sua comunidade de origem. A adaptação dessas pessoas em um novo local se torna uma barreira difícil de ser vencida, muito embora o governo venha construindo uma cultura política sobre o tema, ainda resta um longo percurso a ser alcançado; outro ponto a ser analisado está na questão da não receptividade dos refugiados por algumas comunidades locais, além da questão da dificuldade do acesso aos direitos fundamentais básicos, principalmente em relação à saúde pública,

18 Disponível em: <http://www.acnur.org/t3/portugues/noticias/noticia/acnur-parabeniza-brasil-por-anuncio-de-vistos-humanitarios-para-sirios/>. Acesso em: 27 abr. 2014. 19 Disponível em: <http://oestrangeiro.org/2013/09/11/brasil-disposto-a-receber-mais-refugiados-sirios/>. Acesso em: 12 abr. 2014. 
uma mazela enfrentada também pelos cidadãos brasileiros.

Nota-se que a adoção de ações, estratégias e políticas públicas voltadas ao acolhimento e a integração local dos solicitantes de refúgio e aos refugiados é questão primordial a ser abordada pela União, Estados e Municípios, para que haja de fato a proteção e não a violação de direitos destes grupos de vulneráveis. Diante disso o país poderá ter a certeza de um dever ético e moral cumprido, no sentido de fazer valer a hospitalidade, uma vez que ao abrir fronteiras e prestar o auxílio humanitário aos que se encontram sem pátria, está resgatando uma vida com dignidade. Mostra-se imperioso o papel do acolhimento e da hospitalidade, uma vez que através dos mesmos será possível o acesso igualitário aos direitos fundamentais assegurados pelos instrumentos jurídicos internacionais e pela Constituição Federal de 1988 aos refugiados que se encontram no país. A hospitalidade então deve ser vista como uma das virtudes necessárias para o mundo contemporâneo de deslocamentos e de deslocados.

\section{REFERÊNCIAS}

ACNUR. Disponível em: $<$ http://www. acnur.orgl/>. Acesso em: 10 abr. 2014.

ANDRADE, José H. Fischel. O Brasil e a Proteção de Refugiados: a discussão tem início no Congresso Nacional. 16 Pensando o Brasil, 1996. . José H. Fischel. Regional policy approaches and harmonization: a latin American perspective. International Journal of Refugee Law. Oxford, v. 10, n. 3, p. 389-409, 1998. ARAÚJO, Washington. O desafio de ser refugiado. In: Refugiados: realidade e perspectivas. Rosita Milesi (Org.). Brasília: CSEM/IMDH: Loyola, 2003.

BRASIL. Ministério da Justiça. Disponível em: <http://www.justica.gov. br/portal/ministerio-da-justica/ destaques-noticias/conare-simplica-processo-de-concessao-de-refugio-aos-estrangeiros.htm>. Acesso em: 12 abr. 2014.

CORRÊA, Luiz Felipe de Seixas (Org.). O Brasil nas Nações Unidas. Brasília: FUNAG, 2007.

DERRIDA, Jacques. Anne Duformantelie convida Jacques Derrida a falar da Hospitalidade. Tradução Antônio Romane. São Paulo: Escuta, 2003. . Adeus a Emmanuel Levinas. São Paulo: Perspectiva, 2004.

DOMINGUEZ, Juliana Arantes; BAENINGER, Rosana. Programa de Reassentamento de Refugiados no Brasil. Disponível em: < http://www. migrante.org.br/programadereassen- 
tamento.pdf $>$. Acesso em: 24 abr. 2014.

HOBSBAWM, Eric. Era dos extremos: o breve século XX (1914-1991). 2. ed. Trad. de Marcos Santarrita. São Paulo: Companhia das Letras, 1995. ITAMARATY. Disponível em: $<$ http:// www.itamaraty.gov.br/sala-de-imprensa/notas-a-imprensa/2002/04/08/ refugiados-afegaos $>$. Acesso em: 24 jul. 2013.

MARCOLINI, Adriana. A política brasileira de proteção e de reassentamento de refugiados - breves comentários sobre suas principais características. Rev. bras. polít. int., Brasília, v. 45, n. 1, p. 16070, jan./jun. 2002. Disponível em: $<\mathrm{http}$ //dx.doi.org/10.1590/S003473292002000100008> Acesso em: 10 maio 2014.

MARTIN, Susan. Averting Forced Migration in Countries in Transition. International Migration Review, v. 40, n. 3, p. 34, 2002. Disponível em: $<$ http://onlinelibrary.wiley.com/ doi/10.1111/14682435.00195/abstract?deniedAccessCustomisedMessage $=$ \&userIsAuthenticated $=$ false $>$. Acesso em: 24 jul. 2013.

MELO, Carolina de Campos de. Revisitando o conceito de refúgio: perspectivas para um patriotismo constitucional. In: ARAUJO, Nadia de; ALMEIDA, Guilherme Assis de (Coord.). O Direito Internacional dos Refugiados: uma perspectiva brasileira. Rio de Janeiro: Renovar, 2001.
PEREZ, Daniel Ornar. Os significados dos conceitos de hospitalidade em kant e a problemática do estrangeiro. konvergencias Filosofia y Culturas en Diálogo. ISSN 1669-9092. Afio $I V$, n. 15, Segundo Cuatrimestre 2007. Disponível em: $<$ http://www. konvergencias.net/danieloperez132. pdf $>$. Acesso em: 03 maio 2014.

PINTO, Bibiana Graeff Chagas. In. ACNUR. RAMOS, André de Carvalho, RODRIGUES, Gilberto, ALMEIDA, Guilherme Assis de (Orgs). 60 anos de ACNUR: perspectivas de futuro. São Paulo: Editora CL - A Cultural, 2011.

PINTO, Joseane Mariéle Schuck. A hospitalidade frente o processo de reassentamento solidário aos refugiados. Cadernos IHU Ideias, ano 11, n. 186, 2013. ISSN: 1679-0316. PIOVESAN, Flávia. Temas de Direitos Humanos. São Paulo: Max Limonad, 1998.

PONTE NETO, Cândido Feliciano da. Reassentamento de refugiados no Brasil: Demonstração da solidariedade humanitária internacional - a dignidade recuperada. In: MILESI, Rosita (Org.). Refugiados: realidade e perspectivas. Brasília: CSEM/ IMDH: Loyola, 2003.

RIO GRANDE DO SUL. Secretaria de Direitos Humanos e Justiça do Estado do Rio Grande do Sul. Disponível em: $<$ http://www.sjdh.rs.gov.br/?model=conteudo\&menu $=1 \& \mathrm{id}=1612 \& p g=$. Acesso em: 30 jul. 2013. 